\title{
DECADAL MIXED LAYER SALINITY IN THE SOUTHEASTERN INDIAN OCEAN
}

\author{
Mochamad Riza Iskandar*, Dewi Surinati \\ Physical Oceanography Laboratory, Research Center for Oceanography, Indonesian Institute of Sciences (LIPI), \\ Jakarta, Indonesia \\ *Correspondence author: <moch031@lipi.go.id; iskandarriza@ymail.com>
}

\begin{abstract}
The decadal of mixed layer salinity budget in the southeastern Indian Ocean (SETIO) is evaluated by using monthly gridded reanalysis ocean dataset (Estimated State of Global Ocean for Climate Research (ESTOC)) from January 1960 to December 2014. The evaluation of salinity budget through the examination of atmospheric flux, surface advection, Ekman advection and entrainment terms. The mixed layer salinity (MLS) in the outflow of the ITF shows decadal cycle. The decadal MLS tendency follows the Ekman advection term. The other processes such as atmospheric surface flux, surface advection and entrainment terms are counterbalanced and small correlates to the salinity tendency.
\end{abstract}

Keywords: Mixed Layer Salinity (MLS), decadal, Salinity budget, Southeastern Indian Ocean

\section{INTRODUCTION}

The mixed layer is the upper part of the surface layer where air-sea interaction occurs causing vertically uniform of water properties such as temperature, salinity, thus the density. The mixed layer is marked by a very small vertical properties gradient. The sea surface temperature and sea surface salinity often markedly as the properties in the mixed layer (Rao and Sivakumar, 2003; Sommer et al., 2015; Sun et al., 2019). The mixed layer salinity (MLS) plays an important role in the physical climate and considered as an indicator of atmospheric alteration in the ocean (Grunseich et al., 2011; Rao and Sivakumar, 2003). Its long term variation is believed as a decent signal of the hydrological cycle in the ocean (Zhang et al., 2016). The spatial distribution of MLS not only drawn by atmospheric fluxes but also the oceanic processes such as advection and mixing in the water column (Ren and Riser, 2009). The salt budget in the mixed layer could quantifies the connection between freshwater flux in and out to the system. The salt stored in the system is the key to understanding salinity variability in the body of water (Ren and Riser, 2009).

The outflow region of Indonesian Throughflow (ITF) is located in the southeastern tropical Indian ocean (SETIO) (Gordon, 1986; Gordon and Fine, 1996;
Gordon et al., 2003). This region is important in the air-sea interaction of the Indian Ocean (Ashok et al., 2001; Saji et al., 1999; Wijffels and Meyers, 2004). For instance, the interannual surface temperature and salinity in this region closely related to the Indian Ocean Dipole (Saji et al., 1999), the enhancement of Leeuwin current transport during 2010-2011 Ningaloo Nino also contributed by the anomalous of low salinity in SETIO causing warming in the western Australia coast (Feng et al., 2015). Moreover, the El-Nino and Southern Oscillation (ENSO) could also influence the SETIO through the ITF (Meyers, 1996; Wijffels and Meyers, 2004). The ITF affects the oceanic condition in the SETIO though equatorial and coastal waveguides (Wijffels and Meyers, 2004). The ITF transport have substantial contribution to the freshening of the Indo-Australian basin (Feng et al., 2015; Zhou et al., 2015) and its annual cycle also influences the MLS variation in the SETIO (Zhang et al., 2016). This implies the distribution of sea surface salinity in this region not only constructed by the local air-sea flux but also the local ocean circulation. The freshwater fluxes within this region can be distinguished with the high surface salinity in the Indian Ocean which shows strong meridional salinity gradient characteristics (Qu and Meyers, 2005) 
There are not many studies concerning the MLS in SETIO (Wyrtki, 1961; Zhang et al., 2016), despite the fact that this location is remarkedly one of the crucial areas in the Indian Ocean. The only comprehensive recent study carried out by Zhang et al. (2016). They analyzed the variation of MLS in SETIO on the seasonal and interannual timescale on the different spatial distribution. They define three different regions in the SETIO, the northern part that closes to the Java-Lesser Sunda coast, the middle part where the water spread along the pathways of ITF extended by the South Equatorial Current (SEC) and the southern part near the Australian coast where the Leeuwin current ensues. They found the negative advection anomalies spread along the ITF pathways from the northern to the middle of SETIO and found the MLS becomes fresher in the austral winter. There is positive entrainment counterbalanced by the freshwater advection within this part. Nonetheless, the analysis periods of the composite data that they used only covered the short-term year (2010-2014) and not deal with the longer-term alteration.

This paper aims to expand the previous study from Zhang et al. (2016) concerning the MLS budget in the SETIO. The investigation will focus on the decadal variability in the small area between the northern and middle parts of SETIO (the area defined by Zhang et al. (2016)) where the SEC takes place. To achieve the decadal MLS budget, here we use the gridded reanalysis ocean dataset from Estimated State of Global Ocean for Climate Research (ESTOC). The monthly gridded of Argo data available since 2004 is also used as a comparison to the ESTOC in the last few years. The next section is concerned with the methodology calculating the MLS budget for this study. Then, this paper will present the findings of the research focusing on the decadal MLS budget. Finally, the conclusion gives a brief summary of what controlled most of the decadal MLS budget in the study areas.

\section{MATERIALS AND METHODS}

The salinity and temperature from ocean reanalysis products used in this study is the Estimated State of Global Ocean for Climate Research (ESTOC) from January 1960 to December 2014 (Osafune et al., 2015). This data is constructed by Japan Agency for Marine-Earth Science and Technology (JAMSTEC). ESTOC is four-dimensional variational (4D-VAR) data synthesis system consists of an ocean circulation model with the optimization system. ESTOC is composed of observations data from the World Ocean Database 2009, GTSPP (Global Temperature and Salinity Profile Program) and Argo float. The assimilated elements in ESTOC are subsurface temperature and salinity, Seasurface height anomaly (SSHA), Sea-surface Temperature (SST), and Global Mean Sea Level (GMSL) (Masuda et al., 2010; Osafune et al., 2015). Horizontal resolution of ESTOC is $1^{\circ} \times 1^{o}$ with 46 vertical levels from surface to the bottom.

The Argo data used in this study is the monthly gridded Argo products from JAMSTEC, Grid Point Value of the Monthly Objective Analysis using the Argo data (MOAA-GPV) with $1^{\circ} x 1^{o}$ spatial resolution (Hosoda et al., 2008). The covering area of MOAA-GPV is the global ocean excluding the Marginal Seas. The vertical resolution of MOAA-GPV is 25 levels from 10$2000 \mathrm{dbar}$ at standard pressure levels. The Argo data used in this study from January 2004 to December 2014. This data is used as a comparison to the ESTOC. Both ESTOC and MOAA-GPV can be accessed online (See the online address at acknowledgment section).

$1^{o} \times 1^{o}$ surface freshwater flux from ESTOC is used to estimate the MLS budget of atmospheric freshwater fluxes spanning from January 1960 to December $2014.1^{o} x 1^{o}$ zonal and meridional surface current velocity from ESTOC is used to estimate the advection term. $1^{o} x 1^{o}$ zonal and meridional wind stress from ESTOC is also used to estimate the Ekman advection terms.

The temperature and salinity data were interpolated with $10 \mathrm{~m}$ interval from surface to the bottom using Akima interpolation (Akima, 1970). The area used in this study at $110^{\circ}-115^{\circ} \mathrm{E}$ and $13^{\circ}-17^{\circ} \mathrm{S}$ in SETIO. The location of study area can be seen in Figure 1.

The mixed layer depth (MLD) was calculated from the gridded data. The MLD calculation uses the fixed value of temperature and density as the threshold criterion (Du et al., 
2015). In the fixed temperature criterion, the MLD is a depth where the temperature has decreased by $0.5^{\circ} \mathrm{C}$ associated with the temperature measured at $10 \mathrm{~m}$. In the fixed density criterion, $0.125 \mathrm{~kg} / \mathrm{m}^{3}$ is used for the threshold. MLD used in this paper is the smallest value between MLD calculated from fixed temperature and density criteria since the shallower of the depth represent the MLD. The mixed layer salinity (MLS) and mixed layer temperature (MLT) was calculated as the averaged value at the MLD position.

The mixed layer salinity budget is written in this equation (Ren and Riser, 2009; Zhang et al., 2016),

$$
\frac{\partial S}{\partial t}=\frac{(E-P) S}{h_{m}}-\boldsymbol{u} . \nabla S-\boldsymbol{u}_{\boldsymbol{e}} . \nabla S-\frac{w_{e} \Delta S}{h_{m}}-\text { residue }
$$

where the $E-P$ is surface freshwater flux, $S$ is MLS, $h_{m}$ is the MLD, $\boldsymbol{u}$ is surface current velocity, $\boldsymbol{u}_{e}$ is Ekman velocity, $\nabla \mathrm{S}$ is gradient of MLS, $w_{e}$ is entrainment velocity, and $\Delta \mathrm{S}$ is differences of salinity at MLD and $20 \mathrm{~m}$ below the MLD. The left side in the equation (1) represents the salinity tendency and the right side represent atmospheric freshwater flux, surface advection, Ekman advection, and entrainment terms. The other processes such as lateral diffusion, subsurface processes etc. are categorized in the residual terms. $\boldsymbol{u}_{\boldsymbol{e}}$ and $\nabla \mathrm{S}$ are calculated both zonally and meridionally within the box.

Ekman velocity estimated as,

$$
\boldsymbol{u}_{\boldsymbol{e}}=\frac{\nabla \tau}{\rho_{o} f h_{m}}=\frac{1}{\rho_{o} f h_{m}}\left(\tau_{y}-\tau_{x}\right)
$$

where $\tau_{x}$ and $\tau_{y}$ is zonal and meridional wind stress respectively, $f$ is Coriolis parameter and $\rho_{o}$ is the reference density of seawater $(1025 \mathrm{~kg}$ $\left.m^{-3}\right)$.

Before computing the advection and entrainment terms, the surface current velocity is averaged within the mixed layer. The entrainment velocity calculated following this equation (Ren and Riser, 2009; Stevenson and Niiler, 1983; Zhang et al., 2016),

$$
w_{e}=H\left(\frac{\partial h_{m}}{\partial t}+\nabla \cdot h_{m} v\right)
$$

where $\boldsymbol{v}$ is the velocity including Ekman and surface current velocity. $H$ is the Heaviside function described as,

$$
H(x)= \begin{cases}1, & x \geq 0 \\ 0, & x<0\end{cases}
$$

$x$ represents the element data at certain position. The entrainment (positive) is only considered in the calculation, and detrainment (negative) velocity is set to zero. Since the water flows out the MLD has same properties as MLD, so it doesn't affect the MLS.

\section{RESULTS}

The annual time series of MLS, MLT, MLD and $\triangle S$ anomalies can be seen in Figure 2. The last decade (2004-2014) signal of MLS, MLT, MLD and $\triangle \mathrm{S}$ from MOAA-GPV closely follows the signal from ESTOC. This similar signal represents that ESTOC has good argument to reveal the decadal variability in this study. The mean of whole time periods of MLS, MLT and MLD from MOAA-GPV (ESTOC) are $34.35 p s u(34.36 p s u), 27.89^{\circ} \mathrm{C}$ $\left(27.01^{\circ} \mathrm{C}\right)$ and $37.47 \mathrm{~m}(60.14 \mathrm{~m})$ respectively. The mean MLD from ESTOC two times deeper than Argo even though the time series pattern is similar from 2004-2014. This condition is suspected due to the application of vertical smoothing in the ESTOC system, thus deepening the MLD. The $\triangle \mathrm{S}$ is always negative (not shown in the figure), due to salinity is increases with depth. The mean of $\Delta \mathrm{S}$ from MOAA-GPV (ESTOC) is -0.076psu ($0.047 p s u)$.

Started from 2004 the MLS tend to be fresher until 2012 and becomes saltier again in last few years both in MOAA-GPV and ESTOC (Figure 2). The trend of freshening the MLS from January 2004 to December 2012 is $0.005 p s u / m o n t h$ (MOAA-GPV). The MLT is contrasting with the MLS, when the MLS is fresher (saltier), the MLT tend to be warmer (cooler). The warming trend MLT period can be seen from 2004 to 2012 both in MOAA-GPV and ESTOC. 
The annual MLT generally coincides with MLD, the deeper (shallower) of MLD, the cooler (warmer) of MLT (Figure 2). The salinity and temperature are the main component of the buoyancy forcing of the MLD formation. Temperature and salinity will modify its density. Cold and/or salty water is denser than warm and/or fresh water, the water tends to sink in the denser condition. Thus, the deeper MLD generally coincides with cooler MLT and/or saltier MLS. In the opposite, the warmer temperature and fresher salinity make the ocean more stratified, therefore shallowing the MLD.

The 121-month moving average filter in the time series of MLS, MLT and MLD can be seen in Figure 3. The 10years smoothed ESTOC signal is simply labeled as "decadal" in this study. Figure 3 shows the MLS, MLT and MLD has low-frequency variations. The time series clearly shows there are two fresher periods of MLS in 1970s and 1990s. Interestingly, this fresher period located in the middle of salinification periods in the 1960s, 1980s and 2000s. On the other hand, the MLT signal shows only one cooling periods in 1980s and the warming period occurs in the time before and after. However, the decadal signal of MLT and its budget will not be revealed in this study. The decadal signal of MLD is quite fluctuating, the deepest period occurs around 1990s and the shallowest occurs around 1970s.

The time series of surface freshwater flux, surface current velocity, Ekman velocity, entrainment velocity, and salinity gradient anomalies can be seen in Figure 4. The blue and black line represents annual and decadal signal from low pass filtered data respectively. The lowest (negative) anomalies of surface freshwater flux occurs after 1980s in the whole time periods. Before 1980s, the surface flux anomalies tend to be positive. This figure indicates high local precipitation in the box region mostly occurs after 1980s. The mean of surface freshwater flux from 1990-2014 is $-1.1 \times 10^{-1} \mathrm{~m} / \mathrm{s}$.

Surface current velocity is quite fluctuating on the annual scale. The mean of meridional and zonal velocity from 1960-2014 are $-1.9 \times 10^{-2} \mathrm{~m} / \mathrm{s}$ and $1.5 \times 10^{-2} \mathrm{~m} / \mathrm{s}$ respectively. The mean negative meridional velocity indicating the flow with westward- moving generally brings the water from the Indonesian area toward the Indian Ocean. Since the middle of 1980s there is decadal negative meridional velocity anomalies indicating the westward moving becomes intensify.

Ekman velocity is also quite fluctuating in annual time scale. The meridional and zonal velocity show low-frequency 10 years signal and likely in the opposite. When zonal velocity anomalies negative (positive), the meridional velocity is positive (negative). Mean of meridional and zonal velocity are $-1.7 \times 10^{-2} \mathrm{~m} / \mathrm{s}$ and $1.1 \times 10^{-2} \mathrm{~m} / \mathrm{s}$ respectively.

The entrainment velocity pattern in ESTOC is quite fluctuating. Similar like others, there is change of decadal anomaly pattern since the middle of $1980 \mathrm{~s}$. On the previous decade, the negative anomaly of entrainment velocity is noticeable compare to the decades after which shows positive anomaly. The mean velocity in the whole time periods is $4.80 \times 10^{-6} \mathrm{~m} / \mathrm{s}$. The mean zonal and meridional salinity gradient in ESTOC are $9.2510^{-8} \mathrm{psu} / \mathrm{m}$ and $3.47 \times 10^{-7} \mathrm{psu} / \mathrm{m}$ respectively.

The decadal of salinity tendency and the other four terms including residual terms can be seen in Figure 5. The decadal salinity term (Figure 5a) has positive peak in the middle of 1960s and 1980 s, and negative peak in the middle of 1970s and 1990s. The mean value from atmospheric freshwater flux, surface advection, Ekman advection and entrainment terms are $-6.0 \times 10^{-3} \mathrm{psu} / \mathrm{month}, 3.4 \times 10^{-3} \mathrm{psu} / \mathrm{month}$, $2.4 \times 10^{-3} \quad \mathrm{psu} / \mathrm{month}, \quad$ and $1.0 \times 10^{-3} \mathrm{psu} /$ month respectively.

The atmospheric flux term (cyan line in Figure $5 b$ ) has similar behavior with the surface freshwater flux (Figure 4). There is similar negative (positive) anomaly after (before) the middle 1980s both in surface freshwater flux (Figure 4) and salinity tendency from atmospheric flux term (cyan line in Figure $5 b$ ). The precipitation terms reach maximum in the last decade around. The magnitude of atmospheric terms becoming negative indicating massive additional of freshwater on the recent decades. 
The surface advection term (magenta line in Figure 5b) likely counterbalanced the atmospheric term, before (after) the middle 1980s there is negative (positive) anomaly. The Ekman advection term (red line in Figure 5b) shows decadal cycle with reversal sign anomaly each 10years periods. The variance of Ekman advection is relatively smaller compare to another term.

The entrainment process in the MLD is the product of entrainment velocity and the difference of salinity in MLD and just below of MLD base. The entrainment terms making a positive contribution to the salt budget (mean $1.0 \times 10^{-3} \mathrm{psu} / \mathrm{month}$ ). The entrainment terms in the SETIO tend to make water column saltier. Because the salinity is increase with depth, the upward of near-surface salinity $(20 \mathrm{~m}$ below mixed layer) tend to bring higher salinity from below. The entrainment term (green line in Figure 5b) has positive anomaly since the beginning of 1990s and negative anomaly before 1990s. The signal pattern from this term similar to the entrainment velocity (Figure 4). In the decadal changes, all of four terms give the particular contribution to the salt budget in the SETIO.

Results show that the decadal from all four terms (Figure 5b) is quite fluctuating without making particular dominant that comparable to the decadal salinity tendency term (black line in Figure 5a). However, the correlation between each term to the salinity tendency can be obtained and describe what terms that control most. There is large correlation coefficient between the time series of Ekman advection (red line in Figure $5 b)$ and salinity tendency $(\mathrm{R}=$ $0.53)$. The amplitude of the decadal atmospheric flux term (cyan line in Figure 5b) is large, but the correlation to the decadal salinity tendency term $(\mathrm{R}=0.28)$ show as the second largest. The amplitude of decadal surface advection (magenta line in Figure 5b) is also large, but correlation between the times series of decadal surface advection and salinity tendency term is relatively small $(\mathrm{R}=0.22)$. The amplitude of entrainment times (green line in Figure $5 \mathrm{~b}$ ) is also quite large, but the correlation to the salinity tendency show as the smallest $(\mathrm{R}=0.07)$.

\section{DISCUSSION}

The MLS budget analysis from ESTOC data revealed that the Ekman advection is primarily responsible for the decadal MLS throughout the analysis period, although with small amplitude. The surface atmospheric flux (with high amplitude) has a negative anomaly since the mid-1980s. This signal is counteracted with surface advection and entrainment process (both with moderate amplitude) that have positive anomaly since the mid-1980s. Thus, the effects of atmospheric flux term likely to be balanced by surface advection and entrainment terms. In other words, the remaining process is Ekman advection which influences the amount of tendency. In the beginning of 1960s, the surface atmospheric flux has big positive anomaly and likely play the significant role in the tendency (Figure 5).

Analysis of ESTOC has confirmed that the ocean dynamics is important to governing the salinity changes in SETIO. However, there is no dominant terms related to the salinity tendency, all of the terms work on their portions to govern the salinity changes in SETIO.

Residual term (Figure 5c) is relatively small indicating the other processes except the four terms are not so dominant to the salinity tendency in the small box of SETIO. Previous studies also show the seasonal and annual MLS changes in SETIO (Zhang et al., 2016) are mostly controlled by air-sea freshwater forcing, vertical mixing and lateral advection.

\section{CONCLUSION}

The decadal MLS tendency calculation shows the MLS changes in SETIO mostly controlled by the Ekman advection. The other terms such as atmospheric flux, entrainment and surface advection terms are relatively not correlated to the salinity tendency. Generally, the four terms are not so dominant to the decadal salinity tendency. Likely there is counteracting process between atmospheric flux, surface advection and entrainment processes that balance the decadal salinity tendency. However, the salt budget evaluation in this study is just giving the basics examination of decadal variability of MLS in this area. The other physical term that is not used in the tendency formulation, such as lateral 
diffusion, subsurface processes, mixing, etc. are relatively small especially in the early decades (shown in the residual terms) compared to four contributor terms. The coverage of monthly ESTOC data could give the insight to describe the physical controlling process of the mixed layer salinity within different temporal time scale. This salinity budget calculation can be applied in the Indonesian region to know the seasonal, annual and even decadal contributors to the salinity tendency. By applying in Indonesian seas, the MLS budget calculation will be more interesting and challenging because it involves other physical processes such as vertical mixing and upwelling.

\section{ACKNOWLEDGMENT}

The author would like sincerely thanks to Ryohei Yamaguchi from Tohoku University for the helpful discussions. The author was also grateful to the reviewers for the valuable comments. All of the data used in this paper can be accessed online. The information of MOAAGPV is available at http://www.jamstec.go.jp/ARGO/argo_web/arg $\mathrm{o} /$ ?page $\mathrm{id}=83 \&$ lang=ja. The information of ESTOC is available at http://www.godac.jamstec.go.jp/estoc/e/.

\section{REFERENCES}

Akima, H. (1970). A New Method of Interpolation and Smooth Curve Fitting Based on Local Procedures. J. ACM, 17(4), 589-602. doi:10.1145/321607.321609

Ashok, K., Guan, Z., and Yamagata, T. (2001). Impact of the Indian Ocean dipole on the relationship between the Indian monsoon rainfall and ENSO. Geophysical Research Letters, 28(23), 4499-4502. doi:10.1029/2001GL013294

Du, Y., Zhang, Y., Feng, M., Wang, T., Zhang, N., and Wijffels, S. (2015). Decadal trends of the upper ocean salinity in the tropical Indo-Pacific since mid-1990s. Scientific Reports, 5, 16050. doi:10.1038/srep16050
Feng, M., Benthuysen, J., Zhang, N., and Slawinski, D. (2015). Freshening anomalies in the Indonesian throughflow and impacts on the Leeuwin Current during 2010-2011. Geophysical Research Letters, 42(20), 8555-8562. doi:10.1002/2015GL065848

Gordon, A. L. (1986). Interocean exchange of thermocline water. Journal of Geophysical Research: Oceans, 91(C4), 5037-5046. doi:10.1029/JC091iC04p05037

Gordon, A. L., and Fine, R. A. (1996). Pathways of water between the Pacific and Indian oceans in the Indonesian seas. Nature, 379, 146. doi:10.1038/379146a0

Gordon, A. L., Susanto, R. D., and Vranes, K. (2003). Cool Indonesian throughflow as a consequence of restricted surface layer flow. Nature, 425(6960), 824-828.

Grunseich, G., Subrahmanyam, B., Murty, V. S. N., and Giese, B. S. (2011). Sea surface salinity variability during the Indian Ocean Dipole and ENSO events in the tropical Indian Ocean. Journal of Geophysical Research: Oceans, 116(C11). doi:doi:10.1029/2011JC007456

Hosoda, S., Ohira, T., and Nakamura, T. (2008). A monthly mean dataset of global oceanic temperature and salinity derived from Argo float observations. JAMSTEC Report of Research and Development, 8, 4759. doi:10.5918/jamstecr.8.47 (accessed 2017-04-10)

Masuda, S., Awaji, T., Sugiura, N., Matthews, J. P., Toyoda, T., Kawai, Y., Doi, T., Kouketsu, S., Igarashi, H., Katsumata, K., Uchida, H., Kawano, T., and Fukasawa, M. (2010). Simulated Rapid Warming of Abyssal North Pacific Waters. Science, 329(5989), 319-322. doi:10.1126/science.1188703

Meyers, G. (1996). Variation of Indonesian throughflow and the El Niño- 
Southern Oscillation. Journal of Geophysical Research: Oceans, 101(C5), 12255-12263. doi:doi:10.1029/95JC03729

Osafune, S., Masuda, S., Sugiura, N., and Doi, T. (2015). Evaluation of the applicability of the Estimated State of the Global Ocean for Climate Research (ESTOC) data set. Geophysical Research Letters, 42(12), 4903-4911. doi:10.1002/2015gl064538 (accessed 2018-04-18)

Qu, T., and Meyers, G. (2005). Seasonal Characteristics of Circulation in the Southeastern Tropical Indian Ocean. Journal of Physical Oceanography, 35(2), 255-267. doi:10.1175/jpo2682.1

Rao, R. R., and Sivakumar, R. (2003). Seasonal variability of sea surface salinity and salt budget of the mixed layer of the north Indian Ocean. Journal of Geophysical Research: Oceans, 108(C1), 9-1-9-14. doi:doi:10.1029/2001JC000907

Ren, L., and Riser, S. C. (2009). Seasonal salt budget in the northeast Pacific Ocean. Journal of Geophysical Research: Oceans, 114(C12). doi:doi:10.1029/2009JC005307

Saji, N. H., Goswami, B. N., Vinayachandran, P. N., and Yamagata, T. (1999). A dipole mode in the tropical Indian Ocean. Nature, 401(6751), 360-363.

Sommer, A., Reverdin, G., Kolodziejczyk, N., and Boutin, J. (2015). Sea Surface Salinity and Temperature Budgets in the North Atlantic Subtropical Gyre during SPURS Experiment: August 2012-August 2013. Frontiers in Marine Science, 2(107).

doi:10.3389/fmars.2015.00107

Stevenson, J. W., and Niiler, P. P. (1983). Upper Ocean Heat Budget During the Hawaii-to-Tahiti Shuttle Experiment. Journal of Physical Oceanography, 13(10), 1894-1907. doi:10.1175/15200485(1983)013<1894:Uohbdt>2.0. Co;2

Sun, Q., Du, Y., Zhang, Y., Feng, M., Chowdary, J. S., Chi, J., Qiu, S., and $\mathrm{Yu}$, W. (2019). Evolution of Sea Surface Salinity Anomalies in the Southwestern Tropical Indian Ocean During 2010-2011 Influenced by a Negative IOD Event. Journal of Geophysical Research: Oceans, 124(5), 34283445. doi:10.1029/2018jc014580

Wijffels, S., and Meyers, G. (2004). An Intersection of Oceanic Waveguides: Variability in the Indonesian Throughflow Region. Journal of Physical Oceanography, $34(5)$, 1232-1253. doi:10.1175/15200485(2004)034<1232:aioowv>2.0. $\mathrm{co} ; 2$

Wyrtki, K. (1961). Physical oceanography of Southeast Asian waters. Naga Report 2. (pp. 195 ).

Zhang, N., Feng, M., Du, Y., Lan, J., and Wijffels, S. E. (2016). Seasonal and interannual variations of mixed layer salinity in the southeast tropical Indian Ocean. Journal of Geophysical Research: Oceans, 121(7), 4716-4731. doi:doi:10.1002/2016JC011854

Zhou, Q., Duan, W., Mu, M., and Feng, R. (2015). Influence of positive and negative Indian Ocean Dipoles on ENSO via the Indonesian Throughflow: Results from sensitivity experiments. Advances in Atmospheric Sciences, 32(6), 783-793. doi:10.1007/s00376-0144141-0 
Mar. Res. Indonesia Vol.44, No.2, 2019: 72-81
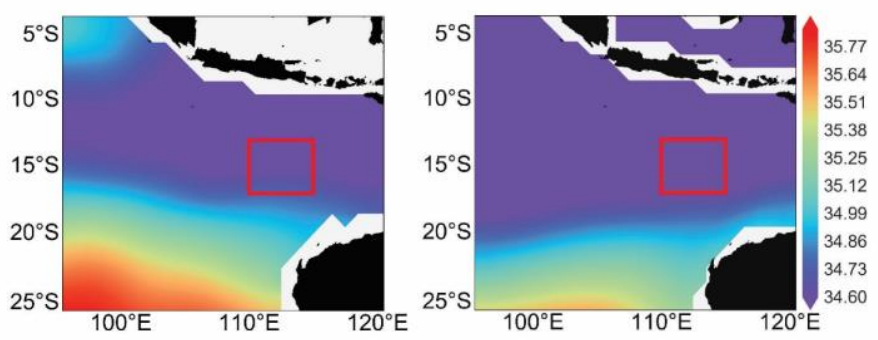

Figure1. Annual mean of surface salinity (psu) in the SETIO from MOAA-GPV (2004-2015) (left) and ESTOC (1960-2014) (right). Location study in the red rectangle area $\left(110^{\circ}-115^{\circ} \mathrm{E}\right.$ and $\left.13^{\circ}-17^{\circ} \mathrm{S}\right)$

a)

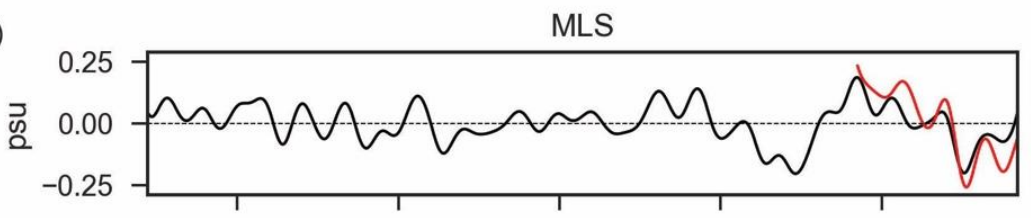

b)

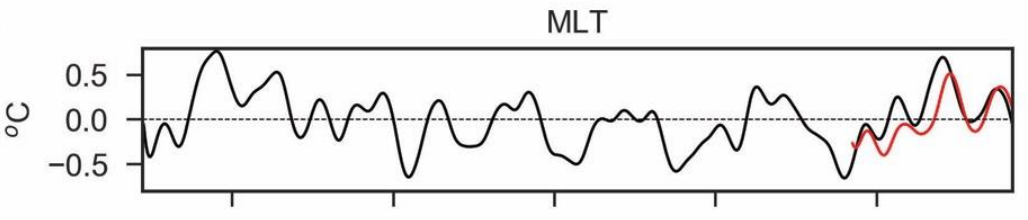

c)

MLD

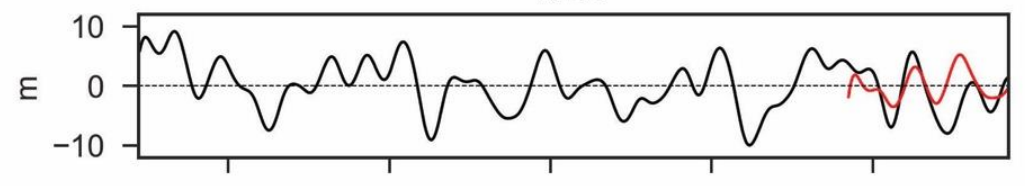

d)

$\Delta \mathrm{S}$

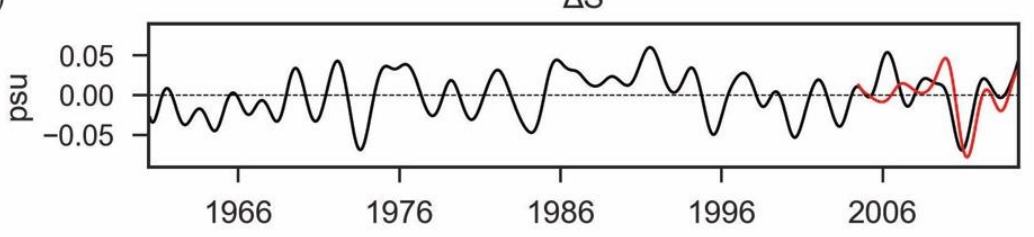

Figure 2. Spatially averaged $\left(110^{\circ}-115^{\circ} \mathrm{E}\right.$ and $\left.13^{\circ}-17^{\circ} \mathrm{S}\right)$ of a) $\operatorname{MLS}(p s u)$, b) MLT $\left({ }^{\circ} \mathrm{C}\right)$, c) $\operatorname{MLD}(m)$, and d) $\Delta S$ (psu) in SETIO from January 1960 to December 2014 in ESTOC (black) and MOAA-GPV (red). 12-month low pass Butterworth filter is applied to remove seasonal signal. 
a)

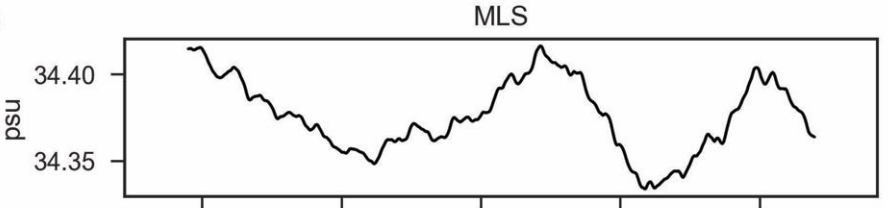

b)

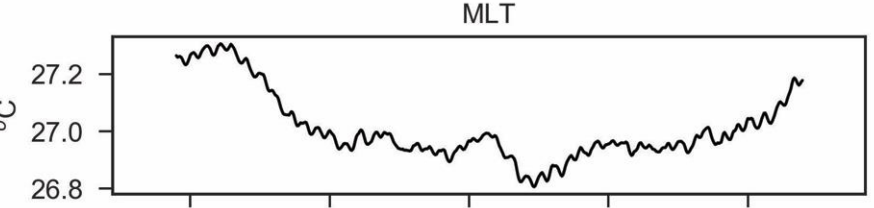

c)

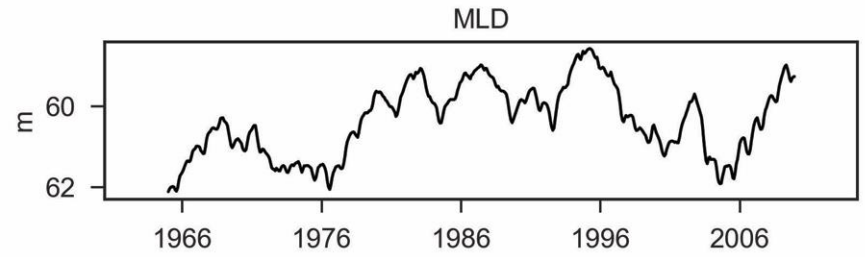

Figure 3. 121-month moving average of a) $\operatorname{MLS}(p s u)$, b) MLT $\left({ }^{\circ} C\right)$, and c) MLD ( $m$ ), from January 1960 to December 2014.

a)

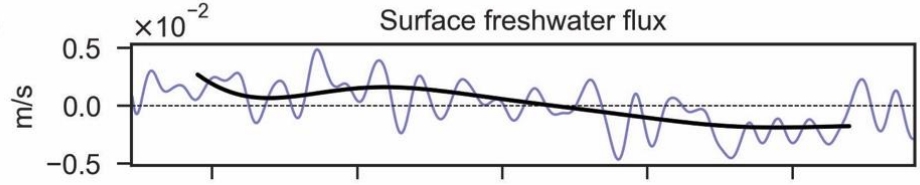

b)

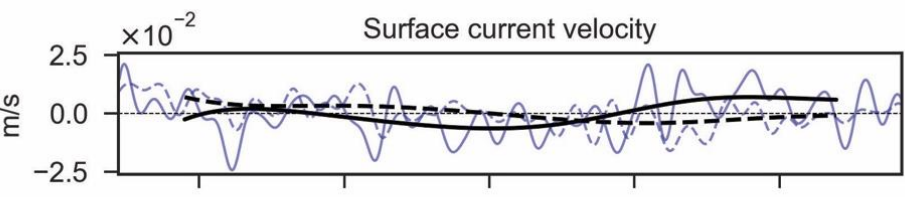

c)

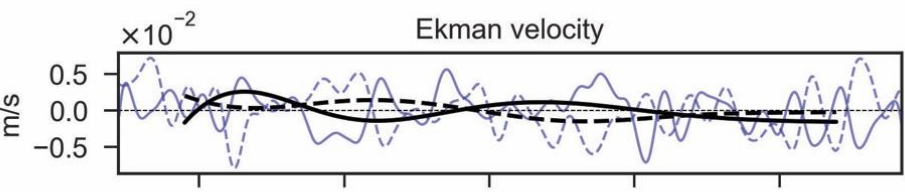

d)

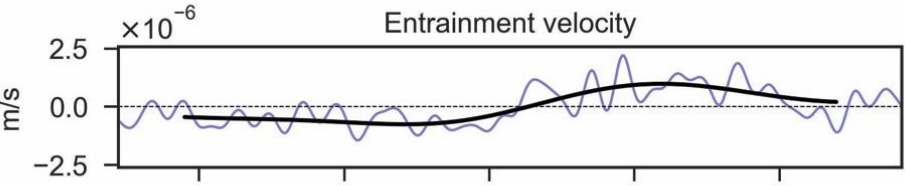

e)

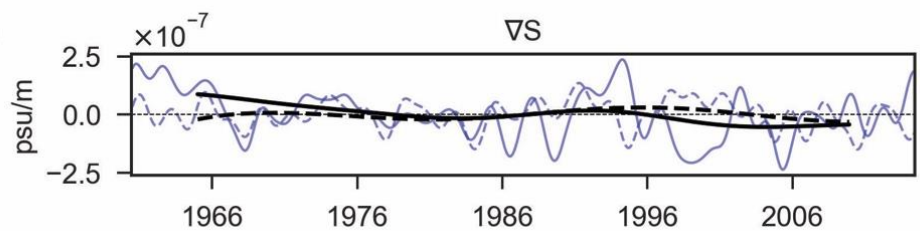

Figure 4. Spatially averaged $\left(110^{\circ}-115^{\circ} \mathrm{E}\right.$ and $\left.13^{\circ}-17^{\circ} \mathrm{S}\right)$ of a) surface freshwater flux $(\mathrm{m} / \mathrm{s})$, b) surface current velocity $(\mathrm{m} / \mathrm{s})$, c) Ekman velocity $(\mathrm{m} / \mathrm{s})$, d) entrainment velocity $(\mathrm{m} / \mathrm{s})$, and e) salinity gradient $(\mathrm{psu} / \mathrm{m})$ in SETIO in January 1960 to December 2014. Blue and black lines represent annual and decadal signal respectively. Thick and dashed line (velocity and salinity gradients) represents zonal and meridional component respectively. 
a)

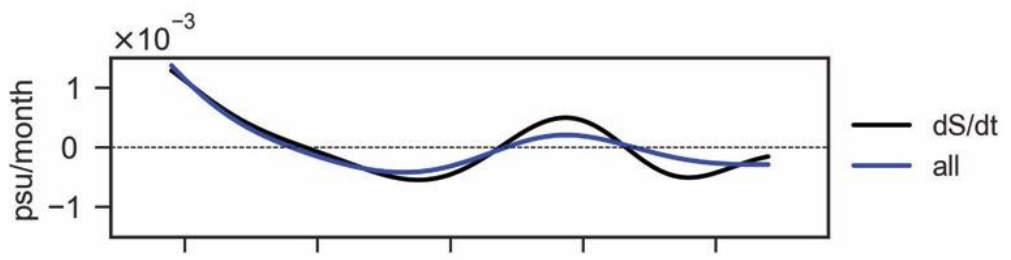

b)

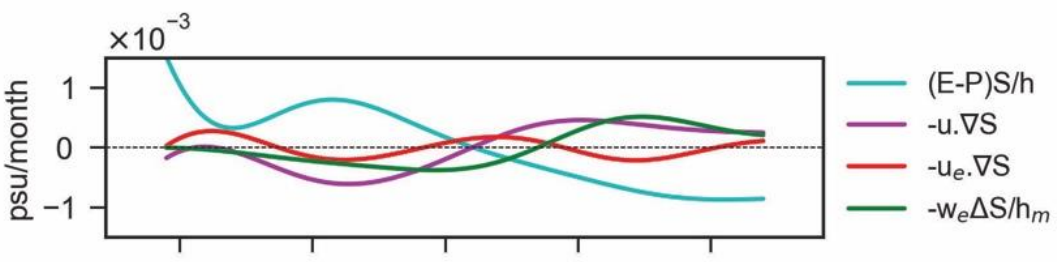

c)

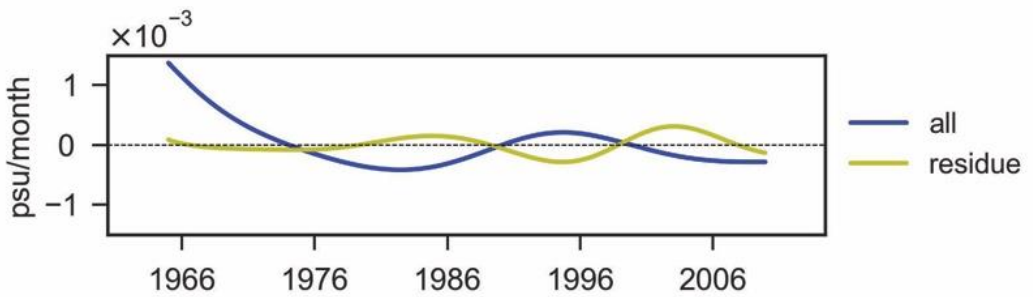

Figure 5. a) Time series of decadal anomaly of salinity tendency term ( $p s u / m o n t h)$ (black) in SETIO $\left(110^{\circ}-115^{\circ} \mathrm{E}\right.$ and $\left.13^{\circ}-17^{\circ} \mathrm{S}\right)$ and sum of atmospheric freshwater flux, surface advection, Ekman advection, and entrainment terms (blue). b) decadal anomaly of atmospheric freshwater flux (cyan), surface advection (magenta), Ekman advection (red), and entrainment terms (green). c) residual terms (yellow) 